\title{
Three New Fungal Leaf Spot Diseases of Spinach in the United States and the Evaluation of Fungicide Efficacy for Disease Management
}

\author{
Bo Liu, ${ }^{1}$ Larry Stein, ${ }^{2}$ Kimberly Cochran, ${ }^{3}$ Lindsey J. du Toit, ${ }^{4}$ Chunda Feng, ${ }^{1}$ and James C. Correll ${ }^{1, \dagger}$ \\ ${ }^{1}$ Department of Plant Pathology, University of Arkansas, Fayetteville, AR 72701 \\ ${ }^{2}$ Department of Horticulture, Texas A\&M University, College Station, TX 77840 \\ ${ }^{3}$ Department of Plant Pathology and Microbiology, Texas A\&M University, College Station, TX 77840 \\ ${ }^{4}$ Department of Plant Pathology, Washington State University, Mount Vernon, WA 98273-4768
}

\begin{abstract}
Leaf spot diseases of spinach, caused by Colletotrichum spinaciae, has become a major production constraint in several production areas, including Texas, in recent years. Leaf spot symptoms were observed in several fields in Texas in 2016 and 2017, with typical anthracnose-like symptoms and leaves with small, circular, and sunken lesions that appeared similar to injury from windblown sand. The lesions were plated on potato dextrose agar, from which fungal cultures were recovered. The fungi were identified based on morphology and sequence analysis of the introns of glutamate synthetase and glyceraldehyde-3-phosphate dehydrogenase (for isolates determined to be Colletotrichum spp.) and the internal transcribed spacer ribosomal DNA (for isolates determined to be Myrothecium spp.). Based on foliar symptoms, fungal colony and spore morphology, pathogenicity tests of fungal isolates on the spinach cultivar 'Viroflay', and DNA sequence analysis of the isolates, the symptoms on spinach leaves for two sets
\end{abstract}

Abstract of samples were caused by Colletotrichum coccodes and Colletotrichum truncatum, and leaf spots resembling damage from windblown sand were caused by Myrothecium verrucaria. This is the first report of spinach leaf spot diseases caused by $C$. coccodes, $C$. truncatum, and $M$. verrucaria in the United States. C. coccodes and C. truncatum caused severe symptoms on the spinach cultivar 'Viroflay', whereas M. verrucaria caused symptoms of intermediate severity. Fungicide efficacy tests demonstrated that chlorothalonil, mancozeb, pyraclostrobin, fluxapyroxad + pyraclostrobin, and penthiopyrad were completely effective at preventing leaf spots caused by any of these pathogens when applied $24 \mathrm{~h}$ before inoculation of 'Viroflay' plants in greenhouse trials.

Keywords: Colletotrichum coccodes, Colletotrichum truncatum, fungicide efficacy tests, leaf spot diseases, Myrothecium verrucaria
Spinach (Spinacia oleracea L.) is an economically important leafy vegetable crop grown on approximately 25,000 ha in the United States, with an annual production of approximately 424,000 metric tons (USDA, National Agriculture Statistics Service 2018). Major fresh market spinach production states include California, Arizona, New Jersey, Texas, and Florida (Correll et al. 1994; USDA, National Agriculture Statistics Service 2018). Leaf spot diseases of spinach reduce crop yield and quality and are of significant concern in spinach production in the United States (Correll et al. 1993, 1994; Hernandez-Perez and du Toit 2006; Koike et al. 2001, 2011). In recent years, leaf spot diseases on spinach have become more prevalent in the Winter Garden production area southwest of San Antonio, Texas (Liu et al. 2017, 2020). Dense seeding rates (1.9 to 8.8 million seeds/ha) for fresh market production and higher-than-normal rainfall in this region probably have affected the prevalence of leaf spot diseases (California Foundation for Agriculture in the Classroom 2019; Reed et al. 2010; ). A wide range of leaf spot diseases caused by fungi and oomycetes have been reported on spinach, including anthracnose (Colletotrichum spinaciae $=$ Colletotrichum dematium $\mathrm{f}$. $\mathrm{sp}$. spinaciae) (Correll et al. 1993, 1994), Stemphylium leaf spot (Stemphylium spp.) (Hernandez-Perez and du Toit 2006; Koike et al. 2001), Cladosporium leaf spot (Cladosporium variabile) (Hernandez-Perez and du Toit 2006), Cercospora leaf spot (Cercospora beticola and Cercospora chenopodii) (Dechmani and Goode 1972; Synoground et al. 2020), Myrothecium leaf spot (Myrothecium verrucaria) (Garibaldi et al. 2016;

${ }^{\dagger}$ Corresponding author: J. C. Correll; jcorrell@uark.edu

Funding: The authors thank the California Leafy Greens Research Board, the Texas Spinach Growers Association, Walther Farms, Schafer Ag Services, and Holaday Seed Co. for partial support of this research.

The author(s) declare no conflict of interest.

Accepted for publication 5 August 2020.

(c) 2021 The American Phytopathological Society
Matic et al. 2019), white rust (Albugo occidentalis), and downy mildew (Peronospora effusa $=$ Peronospora farinosa $\mathrm{f}$. sp. spinaciae) (Correll et al. 1994). Determining the causal agent of the various leaf spot diseases on spinach is vital for implementing effective disease management practices. Leafy green vegetable crops such as spinach are often grown at high crop densities, typically with multiple cropping cycles per year, with limited crop rotations, and under sprinkler (overhead) irrigation, all of which favor leaf spot disease development (Gullino et al. 2019).

From 2016 to 2018, diverse foliar leaf spot symptoms were observed on commercial spinach crops in many fields in the Winter Garden area of Texas (Liu et al. 2020). One type of leaf spot symptom resembled anthracnose, with small, circular, water-soaked lesions on young and old leaves. The lesions enlarged and became necrotic, and the affected leaf tissue became papery thin. The lesions often coalesced. Acervuli with black setae were observed in the diseased tissue (Figs. 1A and B). The symptoms were similar to those reported on spinach as being caused by $C$. spinaciae (Liu et al. 2020), but initial observations of the isolate conidial morphology suggested the causal agent was a different species of Colletotrichum. A second type of leaf spot symptom consisted of small, irregular, sunken, grayish spots $\left(0.5\right.$ to $\left.3 \mathrm{~mm}^{2}\right)$, each with a distinct margin. The spinach leaves had symptoms suggesting mechanical injury, for example, from windblown sand (J. C. Correll, unpublished) (Fig. 1C). The symptoms were distinct from those caused by other known pathogens such as C. spinaciae, Stemphylium spp., or C. beticola, which have been shown to be fairly common on spinach in Texas (Liu et al. 2020). The objectives of this research were to determine the causes of the various unusual leaf spot symptoms observed in spinach crops in Texas from 2016 to 2018 and evaluate the efficacy of diverse fungicides, including some biofungicides, against the pathogens that cause these symptoms.

\section{Materials and Methods}

Pathogen isolation and species identification. Up to 50 leaves with leaf spot symptoms were collected from each of six separate farm locations in Texas (three in 2016 and three in 2017) and examined macroscopically and microscopically (Table 1 ). The sample locations were based on reports from commercial growers, extension personnel, or spinach breeders. Subsamples of 50 leaves chosen 
randomly from a given location for each sample were each incubated in a moist chamber for 1 to 5 days at $22^{\circ} \mathrm{C}$ to evaluate microbial growth. For one of the sites, Farm 6 sampled in 2017, only 10 leaf samples were collected because of the low incidence of symptoms in that field. The leaves were then examined with a dissecting microscope and a compound microscope at $\leq 500 \times$ magnifications to observe asexual or sexual fungal structures for genus and preliminary species identification. Small sections of the diseased tissue $\left(3 \mathrm{~mm}^{2}\right)$ from each leaf were surface-sterilized in $10 \%$ bleach $(0.525 \%$ sodium hypochlorite) for $2 \mathrm{~min}$, rinsed in sterilized water, air-dried, and placed into Petri dishes containing potato dextrose agar (PDA) amended with 30 and $100 \mathrm{ppm}$ of rifampicin and ampicillin, respectively. Plates were incubated with a 12-h/12-h light/dark cycle at $22^{\circ} \mathrm{C}$. After 7 to 21 days of incubation, fungal colonies were
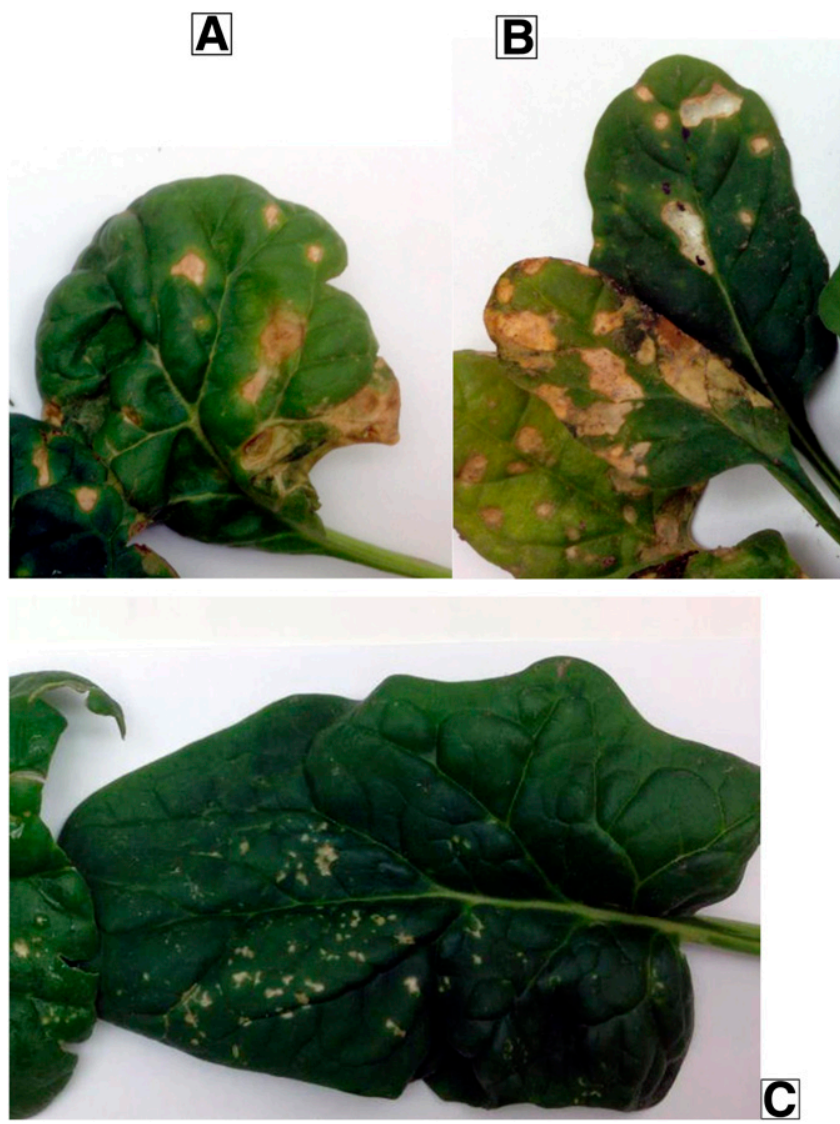

Fig. 1. Symptoms of leaf spot diseases caused by A, Colletotrichum coccodes, B, Colletotrichum truncatum, and C, Myrothecium verrucaria on spinach leaves sampled from growers' fields in Texas in 2016 and 2017. examined. Fungal isolates were identified to species based on morphology and DNA sequencing. For morphological characterization, isolates resembling Colletotrichum spp. and Myrothecium spp. were cultured on PDA for 2 and 3 weeks, respectively. Conidia (25 per isolate) were collected from the center of the Petri dish for each isolate, and the length and width were measured at a magnification of $500 x$ with a compound microscope.

Of 200 isolates of Colletotrichum spp. obtained from the 260 leaf samples, 175 isolates resembled the reported spinach anthracnose pathogen, $C$. spinaciae, based on acervuli, setae, and conidial morphology (Damm et al. 2009; Liu et al. 2020). The remaining 25 isolates that did not resemble $C$. spinaciae morphologically included five isolates from leaves sampled from Farm 1 in 2016 and six isolates from Farm 2 in 2017 that resembled Colletotrichum coccodes morphologically (Sutton 1980), and five isolates from Farm 3 in 2016 and nine isolates from Farm 4 in 2017 that resembled Colletotrichum truncatum morphologically (Sutton 1980). In addition, 25 isolates resembling Myrothecium spp. morphologically (Domsch et al. 1980) were recovered from lesions on leaves sampled from two locations, Farm 5 in 2016 and Farm 6 in 2017 (Table 1). Three representative isolates from each farm location and six isolates of each species were cultured on PDA for 7 days with a 12-h/12-h light/dark cycle at $22^{\circ} \mathrm{C}$. The colony diameters of each isolate growing on PDA were measured in perpendicular directions at the widest point of each colony.

Three putative isolates of $C$. coccodes and three of $C$. truncatum were characterized further by DNA sequencing for species verification. DNA was extracted from each of these fungal isolates using the DNeasy Plant Mini Kit following the manufacturer's instructions (Qiagen, Valencia, CA). The introns of the glutamine synthetase (GS-I) and glyceraldehyde-3-phosphate dehydrogenase (gapdh-I) genes for these isolates were amplified by PCR assay with the GSF1 and GSR1 primers for GS-I and the GDF1 and GDR1 primers for gapdh-I (Guerber et al. 2003; Liu et al. 2007). The internal transcribed spacer (ITS) region of ribosomal DNA (rDNA) was amplified for three putative isolates of Myrothecium by PCR assay with the universal primers ITS1 and ITS4 (White et al. 1990). The PCR products were purified with a Quick PCR purification kit and sequenced directly with the same PCR primers, by Eton Bioscience Inc. (Research Triangle Park, NC). Sequencing reactions were carried out with the ABI PRISM Dye Terminator Cycle Sequence Ready Reaction Kit (Applied Biosystems Inc., Foster City, CA).

The nucleotide sequences of representative isolates were searched by using the BLAST against the database of the National Center for Biotechnology Information for species identification (Altschul et al. 1997). For sequence comparison between the three Colletotrichum spp., the $G S$-I and gapdh-I sequences were aligned with the software LALIGN/PLALIGN (https://fasta.bioch.virginia.edu/fasta) and MAFFT (version 7.463) (https://mafft.cbrc.jp/alignment/server/ spool). In addition, the ITS rDNA sequences of the isolates of $M y r-$ othecium were evaluated with the CBS voucher isolate of $M$. verrucaria (KU845893) and the isolates of two closely related species,

Table 1. Spinach samples from the Winter Garden production area of Texas from which new leaf spot pathogens of spinach were found in 2016 and $2017^{x}$

Isolation frequency (no. of leaves from which the species was isolated/total no. of leaves plated on agar medium)

\begin{tabular}{lllccccc} 
Sample number & Sampling date & Location & Colletotrichum spinaciae & C. coccodes & C. truncatum & Myrothecium verrucaria & $\begin{array}{c}\text { Stemphylium vesicarium } \\
\text { or S. beticola }\end{array}$ \\
\hline $2-3$ & $12 / 7 / 16$ & Farm 1 & $45 / 50^{2}$ & $5 / 50$ & 0 & 0 & 0 \\
$12-1$ & $2 / 28 / 17$ & Farm 2 & $44 / 50$ & $6 / 50$ & 0 & 0 & 0 \\
$3-5$ & $12 / 12 / 16$ & Farm 3 & $45 / 50$ & 0 & $5 / 50$ & 0 & 0 \\
$12-4$ & $2 / 28 / 17$ & Farm 4 & $41 / 50$ & 0 & $9 / 50$ & 0 & 0 \\
$2-4$ & $12 / 7 / 16$ & Farm 5 & 0 & 0 & 0 & $20 / 50$ & $5 / 10$ \\
$11-3$ & $1 / 18 / 17$ & Farm 6 & 0 & 0 & 0 & $5 / 10$
\end{tabular}

$\mathrm{x}$ The disease samples are part of the samples of large-scale survey (Liu et al. 2020).

y Each farm designation represented a separate geographic sampling area.

${ }^{\mathrm{z}}$ Fifty leaves with leaf spots were examined per location, except for Farm 6 in 2017, from which only 10 leaves with lesions were examined. Refer to the main text for details on the isolation procedure. Fungal isolates were identified to species morphologically and by DNA sequencing, as detailed in the main text. 
Myrothecium terrestris (KU845883) (strain CBS 126186) and Myrothecium viridis (KU845898) (strain CBS 449.71).

Pathogenicity tests. Three isolates of each of $C$. coccodes (CcTX1, CcTX-2, and CcTX-3), C. truncatum (CtTX-1, CtTX-2, and CtTX-3), and M. verrucaria (MvTX-1, MvTX-2, and MvTX-3) were tested for pathogenicity on spinach along with three isolates of $C$. spinaciae (Cd-1, Cd-2, and Cd-3) as positive control treatments for spinach leaf spot pathogens (Table 2). The isolates were inoculated onto 30-day-old spinach plants of the cultivar 'Viroflay (Pop Vriend Seed Co., Andijk, The Netherlands). Ten spinach seeds were planted in each pot (diameter, $10 \mathrm{~cm}$; height, $10 \mathrm{~cm}$ ) in $\mathrm{LC} 1$ potting mix (Sungro Horticulture Distribution Inc., Agawam, MA). Stands were thinned to three plants per pot. The isolates of $C$. coccodes, $C$. truncatum, and $C$. spinaciae were cultured on PDA for 2 weeks, and the isolates of $M$. verrucaria were grown for 3 weeks on PDA for collecting conidia. Conidia on PDA plates were dislodged in distilled water added to each plate by scraping the colonies with a sterilized glass spreader. Each conidial suspension was then filtered through two layers of cheesecloth, and the inoculum concentration adjusted to $1 \times 10^{6}$ spores $/ \mathrm{ml}$. Polysorbate surfactant Tween $20(0.01 \%)$ (Sigma-Aldrich, St. Louis, MO) was added to each conidial suspension or to distilled water for the noninoculated control treatment. Plants were inoculated with the relevant spore suspension, with three pots of plants sprayed with approximately $10 \mathrm{ml}$ of inoculum using a Badger Basic Spray Gun (Model 250). All inoculated and control plants were incubated in a mist chamber for $48 \mathrm{~h}$ at 24 to $25^{\circ} \mathrm{C}$ and then moved to a greenhouse $\left(20\right.$ to $\left.30^{\circ} \mathrm{C}\right)$ to observe disease

Table 2. Mean severity of leaf spot caused by Colletotrichum truncatum, $C$. coccodes, and Myrothecium verrucaria recovered from spinach leaves in the Winter Garden area of Texas after artificial inoculation of spinach cultivar 'Viroflay'x

\begin{tabular}{llc}
\hline Pathogen & Isolate & Mean disease severity \\
\hline Colletotrichum spinaciae & Cd-1 & $4.0 \pm 0.1 \mathrm{a}$ \\
C. spinaciae & Cd-2 & $4.0 \pm 0.1 \mathrm{a}$ \\
C. spinaciae & Cd-3 & $4.0 \pm 0.1 \mathrm{a}$ \\
C. truncatum & CtTX-1 & $4.0 \pm 0.1 \mathrm{a}$ \\
C. truncatum & CtTX-2 & $4.0 \pm 0.1 \mathrm{a}$ \\
C. truncatum & CtTX-3 & $4.0 \pm 0.1 \mathrm{a}$ \\
C. coccodes & CcTX-2 & $4.0 \pm 0.1 \mathrm{a}$ \\
C. coccodes & CcTX-1 & $3.9 \pm 0.1 \mathrm{~b}$ \\
C. coccodes & CcTX-3 & $3.7 \pm 0.1 \mathrm{c}$ \\
Myrothecium verrucaria & MvTX-1 & $2.6 \pm 0.1 \mathrm{~d}$ \\
M. verrucaria & MvTX-3 & $2.3 \pm 0.1 \mathrm{e}$ \\
M. verrucaria & MvTX-2 & $2.0 \pm 0.1 \mathrm{f}$ \\
Water (control) & & 0 \\
LSD & & 0.25
\end{tabular}

\begin{tabular}{lrr}
\hline ANOVA factor & $d f$ & $\operatorname{Pr}>F^{\mathrm{z}}$ \\
\hline Repeat experiment & 1 & 0.5599 \\
Isolate & 12 & $<0.0001$ \\
Isolate $\times$ repeat experiment & 13 & 0.9996 \\
\hline
\end{tabular}

${ }^{x}$ Disease severity scale: $0=$ no symptoms on leaves, $1=1$ to $25 \%, 2=26$ to $50 \%, 3=51$ to $75 \%$, and $4=76$ to $100 \%$ of the inoculated leaf area with leaf spots. For each fungal isolate, three 30-day-old plants in each of three replicate pots were inoculated with a suspension of $1 \times 10^{6} \mathrm{spores} / \mathrm{ml}$, incubated at 24 to $25^{\circ} \mathrm{C}$ in a mist chamber for $48 \mathrm{~h}$, and then moved to a greenhouse for observation. Final disease severity was recorded 14 days after inoculation. The midpoint of the percentage leaf spot severity was used for statistical comparison.

${ }^{y}$ Mean \pm standard deviation of leaf spot severity from two repeat experiments. Data from repeated experiments were not significantly different based on a test of homogeneity of variances (Levene's test) for the two experiments. Therefore, the data were combined across repeats for statistical analyses. Means with different letters were significantly different at $P<$ 0.05 based on Fisher's protected least significant difference (LSD). Results for the water control treatment ( $0 \%$ leaf spot severity) were not included in the analyses to avoid heterogeneous variances.

${ }^{z}$ Significance level $(P)$ from the analysis of variance (ANOVA) for disease severity, with the main effects of repeats of the experiment and isolates of the fungus, as well as the interaction between the two main effects. development. Foliar disease severity was recorded 5 to 14 days after inoculation on a scale of 0 to 4 as follows: $0=$ no symptoms on leaves, $1=1$ to $25 \%$ leaf area with symptoms, $2=26$ to $50 \%, 3=$ 51 to $75 \%$, and $4=76$ to $100 \%$ of the inoculated leaf area with leaf spots. The pathogenicity trial was repeated. In addition, 10 randomly selected lesions that developed on spinach leaves 9 to 10 days after inoculation were used to reisolate fungal pathogens for each of the species inoculated, according the procedure described previously. Reisolated fungi were cultured on PDA for 2 to 3 weeks, conidia were collected from the center of the Petri dish for each isolate, and the conidial morphology of reisolated fungi was compared microscopically with the original isolates at a magnification of $500 \times$.

Fungicide evaluation on leaf spot diseases. The spinach cultivar 'Viroflay' was grown in pots ( 10 seeds per pot) in the greenhouse and thinned to three plants per pot for fungicide efficacy testing against the leaf spot pathogens. The isolates CcTX-1 (C. coccodes), CtTX1 (C. truncatum), Cd-1 (C. spinaciae) (positive control pathogen of spinach), and MvTX-1 (M. verrucaria) were each used for the fungicide efficacy trials. The isolates of Colletotrichum were cultured on PDA for 2 weeks, and the isolate of $M$. verrucaria was grown on PDA for 3 weeks before spore suspensions were made.

A total of 19 fungicides and biofungicides were tested for efficacy against each of the three fungal isolates, with each isolate tested in an independent experiment (Table 3). Water was used as a negative control treatment in each experiment. The 19 fungicides evaluated, along with their respective modes of action, active ingredients, and maximum label recommended rates of application, are summarized in Table 3. For the experiment with each pathogen, 30-day-old spinach plants were treated with the various materials $24 \mathrm{~h}$ before being inoculated. Plants were inoculated separately with isolates CcTX-1, CtTX-1, Cd-1, and MvTX-1 according to the same procedures and conditions described for the pathogenicity tests. Severity of leaf spot was recorded 5 to 14 days after inoculation. The experiment with each fungal isolate was repeated once.

Experimental design and statistical analysis. The pathogenicity test and the fungicide trials were each set up in a randomized complete block design with three replications (pots) per treatment. The scoring of leaf spot severity for each plant was converted to a percentage value (midpoints, whereby $0=0 \%, 1=12.5 \%, 2=25 \%, 3=$ $62.5 \%$, and $4=87.5 \%$ ). The percentage scores of the severity ratings were used for statistical analysis (Villarroel-Zeballos et al. 2012). All analyses were performed in Statistical Analysis Systems software (version 8.0; SAS Institute, Cary, NC). Variances of the raw data for the repeat experiments of disease severity were compared via Levene's test for homogeneity under the general linear model procedure (PROC GLM) of SAS version 9.3. Variances of the two experiments were not statistically different for each test; therefore, the raw data for the two repeats of each experiment were combined for subsequent analysis. In addition, data were subjected to analyses of variance (ANOVAs) and mean comparisons via Fisher's protected least significant difference (LSD) $(P=0.05)$ in the PROC GLM of SAS, with the main effects of repeat experiments, replications, and isolates or fungicides and the interaction of repeat experiments with isolates or fungicides. Isolates and fungicides were considered fixed effects, whereas repeats of the trials, replications, and the interactions of trials with isolates or fungicides were considered random effects.

\section{Results}

Pathogen isolation and species identification. Symptoms typical of anthracnose were observed at four of the six Texas spinach production locations sampled: Farms 1 and 3 sampled in 2016, and Farms 2 and 4 sampled in 2017 (Table 1). Based on morphological and molecular characterization of the isolates, $C$. spinaciae was the predominant pathogen recovered from all four farms (Table 1) (Sutton 1980). However, multiple isolates of C. coccodes and C. truncatum were recovered from each of two locations in 2016 (Farms 1 and 3) and two locations in 2017 (Farms 2 and 4) (Table 1).

The isolates of $C$. coccodes produced pale, salmon-colored morphology on PDA plates, with an average colony diameter of $65 \mathrm{~mm}$, after growing for 7 days at $22 \pm 2{ }^{\circ} \mathrm{C}$ (Fig. 2A) and produced 
black microsclerotia after 2 weeks. Acervuli and setae were observed in pure culture after 3 weeks. Conidia were fusiform and straight with tapered ends ( 16 to $23 \times 3.5$ to $4 \mu \mathrm{m}$ ) (Fig. $3 \mathrm{~A}$ ). The morphological characteristics were consistent with the description of $C$. coccodes (Sutton 1980). The cultures of $C$. truncatum initially were light gray and developed dark gray mycelium with an average colony diameter of $76 \mathrm{~mm}$ after 7 days at $22 \pm 2^{\circ} \mathrm{C}$ (Fig. 2B). Acervuli with conidia and dark setae were observed after 2 weeks on PDA. Conidia were hyaline, one-celled, and falcate to nearly straight, with a prominent clear area in the center of highly granular cytoplasm, and measured 22 to $32 \mu \mathrm{m} \times 3.5$ to $4 \mu \mathrm{m}$ (Fig. 3B). The morphological characteristics were consistent with the description of C. truncatum (Sutton 1980).

The colony morphologies of both $C$. coccodes (salmon-colored) and $C$. truncatum (light gray to dark gray) were distinct from that of C. spinaciae (dark gray-olivaceous to olivaceous-black, white margin, covered by very short whitish aerial mycelium) on PDA (Damm et al. 2009). The shape of the conidia of both species also was distinct from those of $C$. spinaciae: Conidia of $C$. spinaciae and $C$. truncatum were curved and tapered along the longitudinal axis, but conidia of $C$. coccodes were straight. Although the conidial sizes of $C$. spinaciae and $C$. coccodes were similar (Damm et al. 2009), the conidia of $C$. truncatum ( 22 to $32 \mu \mathrm{m} \times 3.5$ to $4 \mu \mathrm{m}$ ) were much larger than those of $C$. spinaciae ( 15.5 to 25$) \times 2.5$ to $3.5 \mu \mathrm{m}$ (Damm et al. 2009).

For the leaf samples from two locations that had the appearance of windblown sand damage, isolates of Myrothecium were observed emerging from symptomatic tissue after a prolonged incubation of $\geq 21$ days on PDA. Twenty isolates of this fungus were recovered from 50 lesions from Farm 5 only in 2016, and five isolates were recovered from 10 leaves from Farm 6 sampled in 2017 (Table 1). Cultures of isolates of Myrothecium grew very slowly on PDA, with an average colony diameter of $11 \mathrm{~mm}$ after 7 days. Colonies were white and developed black sporodochia (Fig. 3D) after 8 to 10 days on PDA. Conidia were navicular, limoniform, and aseptate with pointed ends (4 to $6 \mu \mathrm{m} \times 2.1$ to $2.3 \mu \mathrm{m}$ ) (Fig. 3C). The morphological characteristics of the isolates matched those of Myrothecium spp., particularly M. verrucaria (Domsch et al. 1980; Lombard et al. 2016).

Based on BLAST searches, the $G S$-I sequences of the three Texas isolates of $C$. coccodes were $100 \%$ similar to the same region of the sequences of $C$. coccodes in GenBank: JQ682645.
The gapdh-I sequences of the three isolates of $C$. coccodes were $100 \%$ similar to the same region of the sequences of $C$. coccodes in GenBank: KC790765. The GS-I sequences of the three Texas isolates of $C$. truncatum were $100 \%$ similar to the same region of the sequences of $C$. truncatum in GenBank: KF500930. The gapdh-I sequences of the three Texas isolates of $C$. truncatum were $100 \%$ similar to the sequences of $C$. truncatum in GenBank: MK675260. The three isolates of $C$. coccodes had identical GS-I or gapdh-I sequences, as did the three isolates of $C$. truncatum (data not shown). Therefore, the sequences of one isolate from

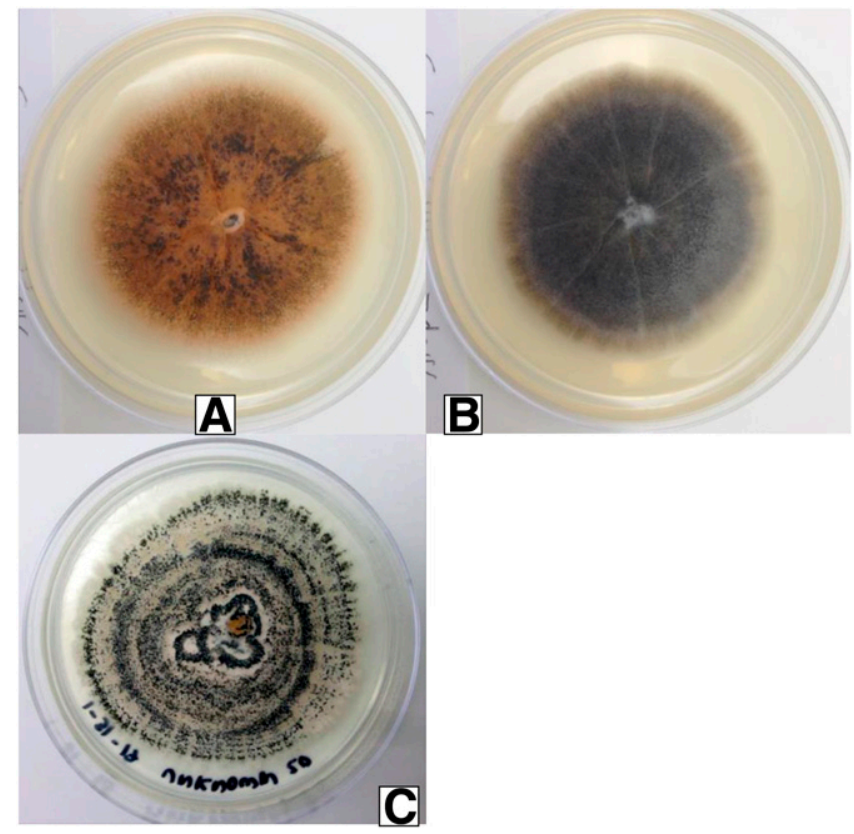

Fig. 2. Colony morphology of A, Colletotrichum coccodes and B, Colletotrichum truncatum 10 days after plating on potato dextrose agar (PDA), and C, Myrothecium verrucaria 1 month after plating on PDA.

Table 3. Fungicides evaluated for control of Colletotrichum coccodes, C. truncatum, and Myrothecium verrucaria inoculated on the spinach cultivar 'Viroflay'

\begin{tabular}{|c|c|c|c|c|}
\hline Fungicide & FRAC code ${ }^{w}$ & Active ingredient & $\begin{array}{l}\text { Recommended dosage } \\
(\mathrm{ml} / \mathbf{0 . 4} \mathrm{ha})^{\mathrm{x}}\end{array}$ & $\begin{array}{l}\text { Equivalent dose used } \\
(\mathrm{ml} \text { or g/50 ml water })^{\mathrm{y}}\end{array}$ \\
\hline Bravo WeatherStik & M5 & Chlorothalonil & 947.2 & 0.83 \\
\hline Dithane F-45 & M3 & Mancozeb & $1,894.4$ & 1.66 \\
\hline Cabrio & 11 & Pyraclostrobin & 453.6 & $0.40 \mathrm{~g}$ \\
\hline Merivon & $7+11$ & Fluxapyroxad + pyraclostrobin & 324.5 & 0.29 \\
\hline Fontelis & 7 & Penthiopyrad & 708.0 & 0.63 \\
\hline Serenade & Biological P06 & Bacillus subtilis & $3,788.8$ & 3.33 \\
\hline Double Nickel & Biological P06 & B. amyloliquefaciens & $1,894.4$ & 1.66 \\
\hline Cueva & M1 & Copper octanoate & $3,788.8$ & 3.33 \\
\hline Revus & 40 & Mandipropamid & 236.6 & 0.21 \\
\hline Top Guard EQ & $3+11$ & Flutriafol + azoxystrobin & 236.8 & 0.21 \\
\hline Trilogy & $2+3+11$ & Iprodione + triticonazole + trifloxystrobin & $3,788.8$ & 3.33 \\
\hline Quadris & 11 & Azoxystrobin & 457.25 & 0.40 \\
\hline Ridomil Gold & 4 & Mefenoxam & 354.0 & 0.31 \\
\hline Switch & $12+9$ & Fludioxonil + cyprodinil & 396.9 & $0.35 \mathrm{~g}$ \\
\hline Tanos & $27+11$ & Cymoxanil + famoxadone & 296.0 & $0.26^{\circ}$ \\
\hline Prophyt + Presidio & $-\mathrm{z}$ & Potassium phosphate + fluopicolide & $2,131.2$ & 1.88 \\
\hline Luna Sensation & $7+11$ & Fluopyram + trifloxystrobin & 224.96 & 0.20 \\
\hline PurGrow $100 \%$ & - & Hypochlorous acid & - & 50 \\
\hline PurGrow $10 \%$ & - & Hypochlorous acid & - & 50 \\
\hline Water (control) & - & Water & - & 50 \\
\hline
\end{tabular}

w Fungicide Resistance Action Committee (FRAC) group. Products in the same FRAC group have the same or similar mode of action, with potential for pathogens to develop cross-resistance to those products (except for products with the letter $M$, which have multiple modes of action with no record of fungicide resistance developing in pathogen populations) (https://www.frac.info).

${ }^{x}$ Recommended dosage on the product label based on applying the product in water at the equivalent rate of 142.5 liters/ha (15 gal/acre).

y Dosage based on the amount ( $\mathrm{ml}$ or $\mathrm{g}$ ) of fungicide in the volume ( $\mathrm{ml}$ ) of carrier (water).

z Dashes indicate the information was not available. 
each species were deposited in GenBank. The GenBank accession number for the $G S$-I intron sequences of CcTX-1 (C. coccodes) is MH047306, and for CtTX-1 (C. truncatum) it is MH047307. The GenBank accession number for the gapdh-I sequence of CcTX-1 (C. coccodes) is MH047308, and for CtTX-1 (C. truncatum) it is MH047309.

The GS-I or gapdh-I sequences of the three species of Colletotrichum isolated from spinach leaves were significantly different from each other based on the DNA sequence alignment. The $G S$-I sequence similarity between $C$. coccodes and $C$. truncatum was $64.8 \%$, the sequence similarity between $C$. coccodes and $C$. spinaciae was $70.2 \%$, and the sequence similarity between $C$. truncatum and $C$. spinaciae was $60.4 \%$. The gapdh-I similarity between $C$. coccodes and $C$. truncatum was $57.0 \%$, between $C$. coccodes and C. spinaciae was $61.3 \%$, and between $C$. truncatum and $C$. spinaciae was $60.8 \%$.

A

B
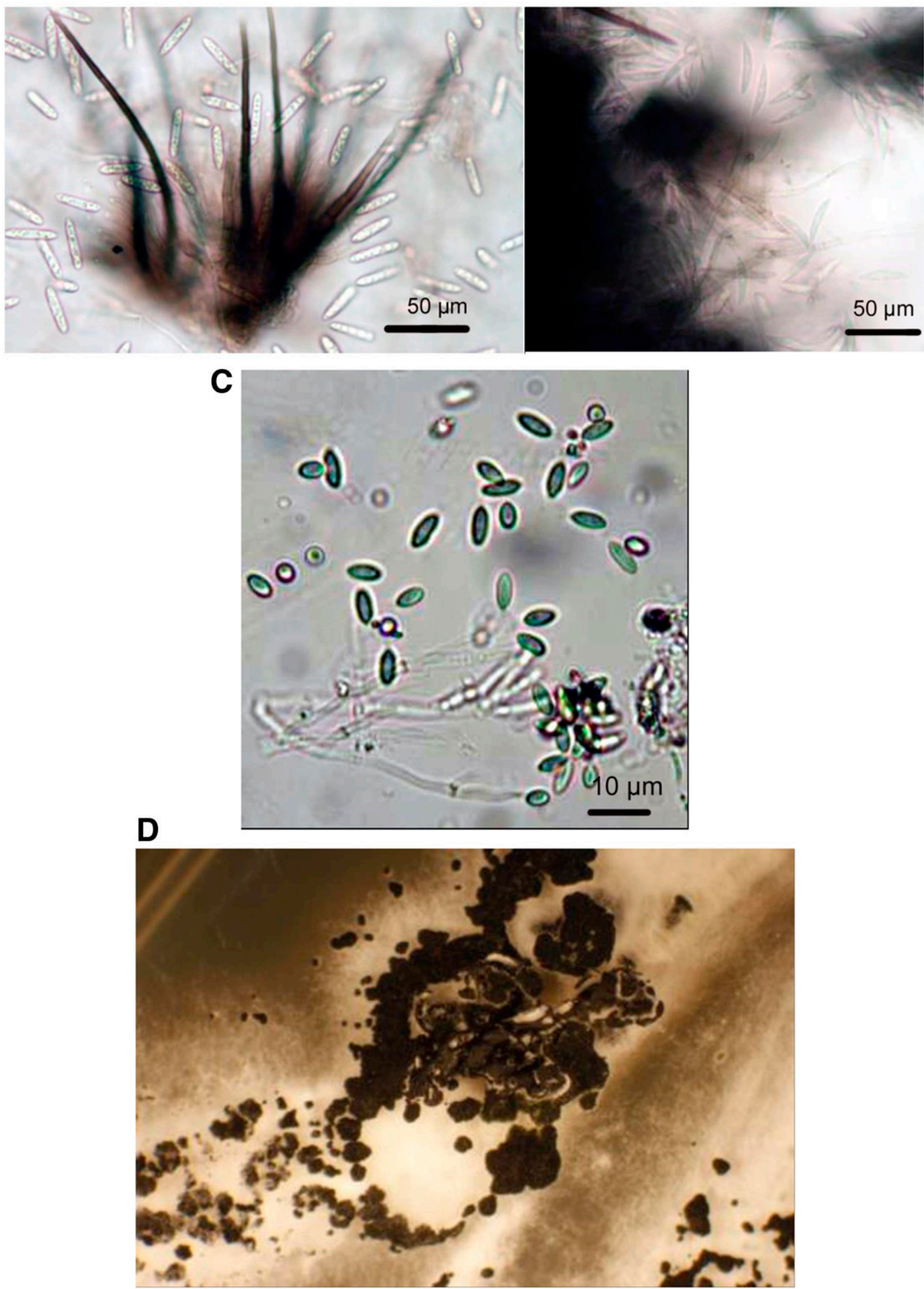

Fig. 3. Conidia and setae of $\mathbf{A}$, Colletotrichum coccodes and B, Colletotrichum truncatum 2 weeks after plating on potato dextrose agar (PDA), and C, conidia and D, black sporodochia of Myrothecium verrucaria (sporodochia appeared 8 to 10 days after plating on PDA, but the photo was taken 1 month after plating). 
BLAST searches showed $100 \%$ homology of the ITS rDNA sequences of isolates MvTX-1, MvTX-2, and MvTX-3 of M. verrucaria to ITS rDNA sequences of $M$. verrucaria deposited in GenBank: AJ301999. The three isolates of $M$. verrucaria had identical ITS rDNA sequences (data not shown). Therefore, the sequence of a single isolate (MvTx-1) was deposited in GenBank (MH047305). The ITS rDNA sequences of the isolates of Myrothecium evaluated were identical to each other and to the CBS voucher isolate of $M$. verrucaria (KU845893) but had a three-nucleotide difference in comparison with ITS rDNA sequences of two closely related Myrothecium species, M. terrestris (KU845883) (strain CBS 126186) and M. viridis (KU845898) (strain CBS 449.71) (Lombard et al. 2016) (data not shown).

Pathogenicity tests. All the plants inoculated with $C$. coccodes, $C$. truncatum, $C$. spinaciae, and $M$. verrucaria in the greenhouse trials developed leaf spot symptoms after 5 to 14 days (Table 2). Leaf spot symptoms did not develop on any of the control plants treated with water. Based on the ANOVAs, there were no significant effects on disease severity of the two repeats of this experiment $(P=0.5599)$, and there was no significant isolate $\times$ repeat experiment interaction on disease severity $(P=0.9996)$. However, there was a significant main effect of fungal isolates on disease severity $(P<0.0001)$ (Table 2). The three representative isolates of each of $C$. coccodes, C. truncatum, and $C$. spinaciae all caused significant leaf damage, with 76 to $100 \%$ of the inoculated leaf surface area showing spots (mean severity category of 4.0). Disease severity on plants inoculated with one isolate of $C$. coccodes (ccTX-2), the three isolates of $C$. truncatum, and the three isolates of $C$. spinaciae was not significantly different (maximum rating of 4.0), whereas disease severity on plants inoculated with the other two isolates of $C$. coccodes was significantly less but still quite severe (3.7 to 3.9) (Table 2). M. verrucaria isolates caused an intermediate severity of leaf spot, with 26 to $50 \%$ of the leaves showing symptoms (mean severity category of 2.0 to 2.6) and with significant differences between the three isolates (Table 2). The symptoms were significantly less severe than those caused by the Colletotrichum spp. MvTX-1 was the most virulent of the three isolates of $M$. verrucaria, followed by MvTX-3 and then MvTX-2. Fungi reisolated from 10 symptomatic leaves inoculated with each isolate had the same morphological features as the original isolates inoculated.

Fungicide evaluation. Isolates of $C$. coccodes (CcTX-1), C. truncatum (CtTX-1), and C. spinaciae (Cd-1) caused severe leaf spotting on the 'Viroflay' control plants treated with water in fungicide efficacy trials $(4.0 \pm 0.1=76$ to $100 \%$ leaf damage $)$. For isolate MvTX-1 of $M$. verrucaria, an intermediate severity of leaf spot was observed on the nontreated control plants $(2.7 \pm 0.1)$, similar to the pathogenicity trials. There was no significant effect on disease severity of the main effect of repeated experiments $(P=0.7275$ for the $C$. coccodes trial, $P=0.8683$ for the $C$. truncatum trial, $P=$ 0.1587 for the $C$. spinaciae trial, and $P=0.4193$ for the $M$. verrucaria trial, respectively), and there was no significant interaction effect of fungicide $\times$ repeat experiment on disease severity $(P=0.5145$ for

Table 4. Mean severity of leaf spot on the spinach cultivar 'Viroflay' treated with different fungicides before inoculation with Colletotrichum coccodes, $C$. truncatum, C. spinaciae, or Myrothecium verrucaria ${ }^{\mathrm{x}}$

\begin{tabular}{|c|c|c|c|c|}
\hline \multirow[b]{3}{*}{ Fungicide } & \multicolumn{4}{|c|}{ Fungal species inoculated (isolate code) } \\
\hline & C. coccodes & C. truncatum & C. spinaciae & M. verrucaria \\
\hline & $\overline{(\text { CcTX-1) }}$ & (CtTX-1) & $(\mathbf{C d}-1)$ & (MvTX-1) \\
\hline Bravo WeatherStik & $0.0 \pm 0.0 \mathrm{a}$ & $0.0 \pm 0.0 \mathrm{a}$ & $0.0 \pm 0.0 \mathrm{a}$ & $0.0 \pm 0.0 \mathrm{a}$ \\
\hline Dithane F-45 & $0.0 \pm 0.0 \mathrm{a}$ & $0.0 \pm 0.0 \mathrm{a}$ & $0.0 \pm 0.0 \mathrm{a}$ & $0.0 \pm 0.0 \mathrm{a}$ \\
\hline Cabrio & $0.0 \pm 0.0 \mathrm{a}$ & $0.0 \pm 0.0 \mathrm{a}$ & $0.0 \pm 0.0 \mathrm{a}$ & $0.0 \pm 0.0 \mathrm{a}$ \\
\hline Merivon & $0.0 \pm 0.0 \mathrm{a}$ & $1.0 \pm 0.1 \mathrm{~b}$ & $0.0 \pm 0.0 \mathrm{a}$ & $0.0 \pm 0.0 \mathrm{a}$ \\
\hline Fontelis & $0.0 \pm 0.0 \mathrm{a}$ & $1.0 \pm 0.1 \mathrm{~b}$ & $1.0 \pm 0.1 \mathrm{~b}$ & $0.0 \pm 0.1 \mathrm{a}$ \\
\hline Serenade & $1.0 \pm 0.1 \mathrm{~b}$ & $1.7 \pm 0.1 \mathrm{c}$ & $2.0 \pm 0.1 \mathrm{~d}$ & $0.7 \pm 0.1 \mathrm{~b}$ \\
\hline Double Nickel & $1.0 \pm 0.1 \mathrm{~b}$ & $2.0 \pm 0.1 \mathrm{~d}$ & $2.0 \pm 0.1 \mathrm{~d}$ & $1.3 \pm 0.1 \mathrm{~d}$ \\
\hline Cueva & $1.0 \pm 0.1 \mathrm{~b}$ & $2.0 \pm 0.1 \mathrm{~d}$ & $2.0 \pm 0.1 \mathrm{~d}$ & $1.3 \pm 0.1 \mathrm{~d}$ \\
\hline Revus & $1.8 \pm 0.1 \mathrm{c}$ & $1.8 \pm 0.1 \mathrm{c}$ & $1.0 \pm 0.1 \mathrm{~b}$ & $1.0 \pm 0.1 \mathrm{c}$ \\
\hline Top Guard EQ & $2.2 \pm 0.1 \mathrm{~d}$ & $2.5 \pm 0.1 \mathrm{e}$ & $0.8 \pm 0.1 \mathrm{~b}$ & $1.0 \pm 0.1 \mathrm{c}$ \\
\hline Trilogy & $3.7 \pm 0.1 \mathrm{~d}$ & $3.7 \pm 0.1 \mathrm{f}$ & $2.7 \pm 0.1 \mathrm{e}$ & $1.5 \pm 0.1 \mathrm{~d}$ \\
\hline Quadris & $3.5 \pm 0.1 \mathrm{~d}$ & $4.0 \pm 0.1 \mathrm{~g}$ & $3.0 \pm 0.1 \mathrm{f}$ & $0.8 \pm 0.1 \mathrm{~b}$ \\
\hline Ridomil Gold & $3.7 \pm 0.1 \mathrm{~d}$ & $3.8 \pm 0.1 \mathrm{f}$ & $4.0 \pm 0.1 \mathrm{~h}$ & $1.0 \pm 0.1 \mathrm{c}$ \\
\hline Switch & $4.0 \pm 0.1 \mathrm{e}$ & $2.0 \pm 0.1 \mathrm{~d}$ & $1.0 \pm 0.1 \mathrm{~b}$ & $1.3 \pm 0.1 \mathrm{~d}$ \\
\hline Tanos & $4.0 \pm 0.1 \mathrm{e}$ & $4.0 \pm 0.1 \mathrm{~g}$ & $3.8 \pm 0.1 \mathrm{~g}$ & $1.0 \pm 0.1 \mathrm{c}$ \\
\hline Prophyt + Presidio & $4.0 \pm 0.1 \mathrm{e}$ & $4.0 \pm 0.1 \mathrm{~g}$ & $1.2 \pm 0.1 \mathrm{c}$ & $1.3 \pm 0.1 \mathrm{~d}$ \\
\hline Luna Sensation & $4.0 \pm 0.1 \mathrm{e}$ & $4.0 \pm 0.1 \mathrm{~g}$ & $3.0 \pm 0.1 \mathrm{f}$ & $0.5 \pm 0.1 \mathrm{~b}$ \\
\hline PurGrow $100 \%$ & $4.0 \pm 0.1 \mathrm{e}$ & $4.0 \pm 0.1 \mathrm{~g}$ & $2.5 \pm 0.1 \mathrm{e}$ & $0.8 \pm 0.1 \mathrm{~b}$ \\
\hline PurGrow $10 \%$ & $4.0 \pm 0.1 \mathrm{e}$ & $4.0 \pm 0.1 \mathrm{~g}$ & $2.5 \pm 0.1 \mathrm{e}$ & $1.0 \pm 0.1 \mathrm{c}$ \\
\hline Water (control) & $4.0 \pm 0.1 \mathrm{e}$ & $4.0 \pm 0.1 \mathrm{~g}$ & $4.0 \pm 0.1 \mathrm{~h}$ & $2.7 \pm 0.1 \mathrm{e}$ \\
\hline LSD & 0.28 & 0.31 & 0.32 & 0.43 \\
\hline ANOVA factor & $\operatorname{Pr}>F^{\mathrm{z}}$ & $\operatorname{Pr}>F$ & $\operatorname{Pr}>F$ & $\operatorname{Pr}>F$ \\
\hline Repeat experiment & 0.7275 & 0.8683 & 0.1587 & 0.4193 \\
\hline Fungicide & $<0.001$ & $<0.001$ & $<0.001$ & $<0.001$ \\
\hline Fungicide $\times$ repeat experiment & 0.5145 & 0.6954 & 0.7206 & 0.9067 \\
\hline
\end{tabular}

${ }^{\mathrm{x}}$ Two types of water controls were used in this experiment. One is that water was used as an isolate for inoculation on the treated and untreated plants; the second is that water was used as a fungicide to treat plants before the pathogen inoculation. Disease severity scale: $0=$ no symptoms on leaves, $1=1$ to $25 \%, 2=26$ to $50 \%, 3=51$ to $75 \%$, and $4=76$ to $100 \%$ leaf area with spots. Three 30-day-old plants in each of 3 replicate pots were inoculated with a suspension of $1 \times 10^{6}$ spores $/ \mathrm{ml}$. Inoculated plants were incubated at 24 to $25^{\circ} \mathrm{C}$ in a mist chamber for $48 \mathrm{~h}$ and then moved to a greenhouse for observation. Symptoms appeared 5 days after inoculation; final disease severity was recorded 14 days after inoculation. Data from repeated experiments were not significantly different based on homogeneity of variance (Levene's test). Therefore, the data were combined across repeat experiments for statistical analyses. The midpoint percentage of the disease severity was used for statistical comparison.

${ }^{y}$ Mean \pm standard deviation of leaf spot severity for the two repeats of the experiment. Treatment means with different letters were significantly different at $P<$ 0.05 based on Fisher's protected least significant difference (LSD).

${ }^{\mathrm{z}}$ Significance level $(P)$ from the analysis of variance (ANOVA) for disease severity, with the main effects of repeats of the experiment and isolates of the fungus, as well as the interaction between the two main effects. 
the $C$. coccodes trial, $P=0.6954$ for the $C$. truncatum trial, $P=$ 0.7206 for the $C$. spinaciae trial, and $P=0.9067$ for the $M$. verrucaria trial, respectively). However, there was a significant fungicide main effect $(P<0.0001)$ for the trials with each of the three fungal isolates (Table 4).

The fungicides Bravo WeatherStik (chlorothalonil), Dithane F-45 (mancozeb), Cabrio (pyraclostrobin), Merivon (fluxapyroxad and pyraclostrobin), and Fontelis (penthiopyrad) were each completely effective at preventing leaf spot symptoms from developing on plants inoculated with $C$. coccodes; lesions were not observed on any of the spinach leaves treated with these products before inoculation with this pathogen (Table 4). Applications of the fungicides Serenade ( $\mathrm{Ba}$ cillus subtilis), Double Nickel (Bacillus amyloliquefaciens), Cueva (copper octanoate), and Revus (mandipropamid) were also highly effective at reducing disease development on plants inoculated with $C$. coccodes (Table 4). Although leaf spots were observed, the spots were smaller and less abundant (mean severity category of 1.0 to 1.8). The remaining fungicides were either ineffective or weakly effective at reducing disease severity caused by $C$. coccodes, as severity of leaf spot ranged from 2.2 to 4.0, the latter for Tanos (cymoxanil + famoxadone), Prophyt (potassium phosphate) + Presidio (fluopicolide), Luna Sensation (fluopyram + trifloxystrobin), and PurGrow (hypochlorous acid) at both rates of application (Tables 3 and 4).

Three fungicides, Bravo WeatherStik, Dithane F-45, and Cabrio, were completely effective at preventing leaf spot symptoms from developing on plants inoculated with $C$. truncatum, similar to the efficacy of these products against $C$. coccodes (Tables 3 and 4). In addition, Merivon, Fontelis, Serenade, Double Nickel, Cueva, Revus, and Switch were also highly effective at reducing disease development on plants inoculated with $C$. truncatum; leaf spots were smaller and less abundant on plants that received these fungicide treatments (mean severity category of 1.0 to 2.0 ). The remaining fungicides were either ineffective or weakly effective against $C$. truncatum (severity of leaf spot ranged from 2.5 to 4.0 ) (Table 4).

The fungicides Bravo WeatherStik, Dithane F-45, Cabrio, and Merivon were completely effective at preventing leaf spot symptoms from developing on plants inoculated with $C$. spinaciae, four of the five products that were completely effective against $C$. coccodes (Table 4). The fungicides Fontelis, Revus, Top Guard EQ, Switch, and Prophyt + Presidio also were highly effective at reducing disease development on plants inoculated with $C$. spinaciae; as leaf spots were reduced in number and size (mean severity category of 1.0 to 1.2) (Table 4). The remaining fungicides were either ineffective or weakly effective against $C$. spinaciae (Table 4 ).

For plants inoculated with $M$. verrucaria, the fungicides Bravo WeatherStik, Dithane F-45, Cabrio, Merivon, and Fontelis were completely effective at preventing leaf spot symptoms from developing, the same five products that were completely effective against $C$. coccodes (Table 4). The other fungicides were all highly effective at reducing leaf spot severity caused by the isolate of $M$. verrucaria (mean severity category of 1.0 to 1.8 compared with 2.7 for the control plants treated with water only before inoculation with this pathogen) (Table 4).

\section{Discussion}

Anthracnose of spinach typically is caused by $C$. spinaciae (formerly $C$. dematium f. sp. spinaciae) and is a major leaf spot disease that has been reported from most spinach production areas in the United States, including Texas (Correll et al. 1993, 1994; Liu et al. 2017, 2020). In a survey of leaf spot pathogens in Texas, anthracnose was the predominant leaf spot disease (Liu et al. 2020). Isolations, morphological and molecular data, and pathogenicity tests confirmed that two additional Colletotrichum spp., C. coccodes and C. truncatum, caused anthracnose of spinach in the Winter Garden area of Texas in 2016 and 2017, and these isolates were demonstrated to cause leaf damage comparable to that caused by $C$. spinaciae (Liu et al. 2020). Although initial surveys in Texas indicated that $C$. spinaciae was the predominant anthracnose pathogen (Liu et al. 2017), a more widespread and systematic survey over several years may be needed to determine the relative prevalence and importance of
C. coccodes and $C$. truncatum on spinach. To our knowledge, this is the first report of anthracnose of spinach caused by $C$. coccodes or C. truncatum in the United States. Although correct species identification of the pathogen is critical for effective control of anthracnose because the different species might differ in sensitivity to various fungicides, this study showed that a number of products were highly effective against all three species.

Both $C$. coccodes and $C$. truncatum have a broad host range on horticultural and field crops as well as weeds. C. coccodes is the causal agent of anthracnose on leaves, stems, and fruits of many plant species, including onion (Allium cepa), potato (Solanum tuberosum), tomato (Solanum lycopersicum), chili (Capsicum annuum), mint (Mentha arvensis) (Hyde et al. 2009), and weeds (Raid and Pennypacker 1987). The fungus can cause significant losses to the yield and quality of potato tubers (Lees and Hilton 2003) and tomato fruit (Dillard and Cobb 1998; Sanogo et al. 2003). C. truncatum has been reported as an important anthracnose pathogen of legume crops such as bean (Phaseolus lunatus and Phaseolus vulgaris), soybean (Glycine max), peanut (Arachis hypogea), lentil (Lens culinaris), and alfalfa (Medicago sativa) (Boyette 1991). C. truncatum is an important pathogen on such crops as chilli pepper (Capsicum annuum and Capsicum frutescens), pepper (C. annuum), and several other hosts in a wide range of plant families (Boyette 1991; Damm et al. 2009; Hyde et al. 2009). The wide host range of these two species of Colletotrichum might pose a challenge for the control of anthracnose on spinach. Determining the sources of primary inoculum of these anthracnose pathogens, including alternative hosts, may be critical for effective integrated management of spinach anthracnose.

Based on isolations of $M$. verrucaria from spinach crops in Texas that displayed symptoms suggestive of mechanical injury such as wind- and sand-blasting, it is possible this pathogen can be overlooked in routine isolations from spinach leaves. Colonies were not observed on agar plates for $\geq 21$ days after incubation of leaf spots on PDA. Thus, one might conclude that the observed damage is related to chemical burn or some other abiotic disorder such as sandblasting. Results in this study of isolations from leaf symptoms, fungal colony and spore morphology, pathogenicity tests on 'Viroflay', and ITS rDNA sequence analysis indicated that $M$. verrucaria was the pathogen responsible for these symptoms on spinach leaves from two farms in Texas. The leaf symptoms were similar to the ones of sand damage in the field condition, possibly because of the dry conditions in the Winter Garden area compared with greenhouse condition, the lesions were restricted in the infected areas of leaves and cannot develop to full size, as the ones in greenhouse condition do. To our knowledge, this is the first report of leaf spot caused by $M$. verrucaria on spinach in the United States, and it complements a previous report from Italy (Garibaldi et al. 2016; Matic et al. 2019). However, more research is needed to assess whether mechanical damage to the leaves may have facilitated infection by this fungus under field conditions.

M. verrucaria has been isolated from soil, air, and plant materials (Domsch et al. 1980). It is a facultative parasite of numerous plants, including peanut (Arachis hypogaea L.), cucumber (Cucumis sativus), soybean, cotton (Gossypium hirsutum), sunflower (Helianthus annuus), birdfoot trefoil (Lotus corniculatus), tomato, alfalfa, rice (Oryza sativa), red clover (Trifolium pratense), and corn (Zea mays). In addition, $M$. verrucaria was demonstrated to be pathogenic to several weed species, including Euphorbia spp. and reed canarygrass (Phalaris arundinacea) (Yang and Jong 1995). Therefore, M. verrucaria might be ubiquitous in environments in which spinach is grown, including on other hosts. Research is needed to determine the prevalence of this pathogen on spinach, the impact of the pathogen on spinach yields, and best methods for disease management.

Fungicides can be an effective approach for reducing the impacts of leaf spot diseases in conventional spinach production. This study demonstrated that several fungicides, such as Bravo WeatherStik (chlorothalonil), Dithane F-45 (mancozeb), Cabrio (pyraclostrobin), Merivon (fluxapyroxad and pyraclostrobin), and Fontelis (penthiopyrad), were highly effective at suppressing leaf spots caused by four fungal pathogens of spinach in this study, the three Colletotrichum 
species and $M$. verrucaria, under greenhouse conditions. In addition, the biofungicides Serenade (B. subtilis) and Double Nickel (B. amyloliquefaciens) showed some efficacy at suppressing these leaf spot diseases under the conditions of the greenhouse tests in this study. Biofungicides might be valuable under organic spinach production conditions or under low disease pressure. However, fungicide evaluations under field conditions are needed to verify efficacy. The biology and epidemiology of the three newly found pathogens of spinach in this study should also be examined in order to elucidate the life cycles of the pathogens, sources of primary inoculum, and environmental conditions that favor disease development.

\section{Literature Cited}

Altschul, S. F., Madden, T. L., Schäffer, A. A., Zhang, J., Zhang, Z., Miller, W., and Lipman, D. J. 1997. Gapped BLAST and PSI-BLAST: a new generation of protein database search programs. Nucleic Acids Res. 25:3389-3402.

Boyette, D. 1991. Host range and virulence of Colletotrichum truncatum, a potential mycoherbicide for hemp sesbania (Sesbania exaltata). Plant Dis. 75:62-64.

Correll, J. C., Morelock, T. E., Black, M., Koike, S. T., Brandenberger, L. P., and Dalnello, F. J. 1994. Economically important diseases of spinach. Plant Dis. 78: 653-660.

Correll, J. C., Morelock, T. E., and Guerber, J. C. 1993. Vegetable compatibility and virulence of the spinach anthracnose pathogen, Colletotrichum dematium. Plant Dis. 77:688-691.

Damm, U., Woudenberg, J. H. C., Cannon, P. F., and Crous, P. W. 2009. Colletotrichum species with curved conidia from herbaceous hosts. Fungal Divers. 39:45-87.

Dechmani, U., and Goode, M. J. 1972. Spinach anthracnose in the Arkansas River Valley. Ark. Farm Res. 21:12.

Dillard, H. R., and Cobb, A. C. 1998. Survival of Colletotrichum coccodes in infected tomato. Plant Dis. 82:235-238.

Domsch, K. H., Gams, W., and Anderson, T. H. 1980. Page 481 in: Compendium of Soil Fungi. Academic Press, New York.

Garibaldi, A., Gilardi, G., Franco-Ortega, S., and Gullino, M. L. 2016. First report of leaf spot of spinach (Spinacia oleracea) caused by Myrothecium verrucaria in Italy. Plant Dis. 100:8

Guerber, J. C., Liu, B., Correll, J. C., and Johnston, P. R. 2003. Characterization of diversity in Colletotrichum acutatum sensu lato by sequence analysis of two gene introns, mtDNA and intron RFLPs, and mating compatibility, mtDNA and intron RFLPs, and sequence analysis of two gene introns. Mycologia 95:872-895.

Gullino, M. L., Gilardi, G., and Garibaldi, A. 2019. Ready-to-eat salad crops: a plant pathogen's heaven. Plant Dis. 103:2153-2170.

Hernandez-Perez, P., and du Toit, L. J. 2006. Seedborne Cladosporium variabile and Stemphylium botryosum in spinach. Plant Dis. 90:137-145.

Hyde, K. D., Cai, L., Cannon, P. F., Crouch, J. A., Crous, P. W., Damm, U., Goodwin, P. H., Chen, H., Johnston, P. R., Jones, E. B. G., Liu, Z. Y., McKenzie, E. H. C., Moriwaki, J., Noireung, P., Pennycook, S. R., Pfenning, L. H., Prihastuti, H., Sato, T., Shivas, R. G., Tan, Y. P., Taylor, P. W. J., Weir, B. S., Yang, Y. L., and Zhang, J. Z. 2009. Colletotrichum names in current use. Fungal Divers. 39:147-182.
Koike, S. T., Cahn, M., Cantwell, M., Fennmore, S., LeStrange, M., Natwick, E. Smith, R. F., and Takele, E. 2011. Spinach production in California. UC Vegetable Research \& Information Center. https://anrcatalog.ucanr.edu/pdf/ 7212.pdf

Koike, S. T., Henderson, D. M., and Butler, E. E. 2001. Leaf spot disease of spinach in California caused by Stemphylium botryosum. Plant Dis. 85: 126-130.

Lees, A. K., and Hilton, A. J. 2003. Black dot (Colletotrichum coccodes): An increasingly important disease of potato. Plant Pathol. 52:3-12.

Liu, B., Feng, C. D., Stein, L., du Toit, L., and Correll, J. C. 2017. Survey of spinach leaf spot diseases in Texas. Phytopathology 107:101 (Abstr.)

Liu, B., Stein, L., Cochran, K., du Toit, L. J., Feng, C. D., Dhillon, B., and Correll, J. C. 2020. Characterization of leaf spot pathogens from several spinach production areas in the U.S. Plant Dis. 104:1994-2004.

Liu, B., Wasilwa, L. A., Morelock, T. E., O'Neill, N. R., and Correll, J. C. 2007. Comparison of Colletotrichum orbiculare and several allied Colletotrichum spp. for mtDNA RFLPs, intron RFLP and sequence variation, vegetative compatibility, and host specificity. Phytopathology 97:1305-1314.

Lombard, L., Houbraken, J., Decock, C., Samson, R. A., Meijer, M., Réblová, M., Groenewald, J. Z., and Crous, P. W. 2016. Generic hyper-diversity in Stachybotriaceae. Persoonia 36:156-246.

Matic, S., Gilardi, G., Gullino, M. L., and Garibaldi, A. 2019. Emergency of leaf spot disease on leafy vegetable and ornamental crops caused by Paramyrothecium and Albifimbria species. Phytopathology 10:1-9.

Raid, R. N., and Pennypacker, S. P. 1987. Weeds as hosts for Colletotrichum coccodes. Plant Dis. 71:643-646.

Reed, J. D., Woodward, J. E., Ong, K. L., Black, M. C., and Stein, L. A. 2010. First report of Stemphylium botryosum on spinach in Texas. Plant Dis. 94:1377.

Sanogo, S., Stevenson, R. E., and Pennypacker, S. P. 2003. Appressorium formation and tomato fruit infection by Colletotrichum coccodes. Plant Dis. 87:336-340.

California Foundation for Agriculture in the Classroom. 2019. Commodity fact sheet: spinach. https://cdn.agclassroom.org/ca/resources/fact/spinach.pdf

Sutton, B. C. 1980. Pages 526-537 in: The Coelomycetes: Fungi Imperfecti With Pycnidia, Acervuli and Stromata. CAB International, Wallingford, U.K.

Synoground, T., Batson, A., Derie, M., Koenick, L. B., Pethybridge, S. J., and du Toit, L. J. 2020. First report of Cercospora leaf spot caused by Cercospora chenopodii on Spinacia oleracea in the USA. Plant Dis. 104:976.

USDA, National Agriculture Statistics Service. 2018. Vegetables 2018 Summary National Agricultural Statistics Service, Washington, DC. https://downloads usda.library.cornell.edu/usda-esmis/files/02870v86p/gm80j322z/5138jn50j/ vegean19.pdf Accessed 11 November 2019

Villarroel-Zeballos, M. I., Feng, C. D., Iglesias, A., du Toit, L. J., and Correll, J. C. 2012. Screening for resistance to Verticillium wilt in spinach and isolation of Verticillium dahliae from seed of spinach accessions. HortScience 47: 1297-1303.

White, T. J., Bruns, T., Lee, S. B., and Taylor, J. W. 1990. Amplification and direct sequencing of fungal ribosomal RNA genes for phylogenetics. Pages 315-322 in: PCR Protocols: A Guide to Methods and Application. M. A. Innis, D. H. Gelfand, and J. J. Snisky, eds. Academic Press, Inc., New York, NY.

Yang, S. M., and Jong, S. C. 1995. Host range determination of Myrothecium verrucaria isolated from leafy spurge. Plant Dis. 79:994-997. 